\title{
Starting with a Look into the Face
}

Although the year starts with darker clouds than expected, the emerging crisis creates opportunities for new directions, not only in the automobile industry, but also in skin research.

We are planning some changes to the ISP homepage (www. isp-society.org). We wish all of you a productive year with time in between to enjoy some reading.

At this point we would like to thank all the authors who submitted their manuscripts to our journal in 2008. The quality of the journal depends very much on you. Furthermore, a peer reviewed journal needs high profile reviewers, and so we thank those who have reviewed manuscripts in 2008. The complete list of reviewers is published on page 2 . We would also like to thank our readers for choosing Skin Pharmacology and Physiology as one of their sources of scientific information. The increasing ISI impact factor is one of the indicators that we are on track. However, improvement is always possible and necessary, and so we would like to encourage readers, authors and reviewers to give us feedback with your wishes and needs that should be addressed. Please, drop us an e-mail.

In the current issue, Zastrow and co-workers (Skin Pharmacol Physiol 2009;22:31-44) characterized the light-induced free radical formation in ex vivo human skin. The authors could show an induction of excess free radicals, especially reactive oxygen species in ex vivo human skin under the influence of light in the range of $280-700 \mathrm{~nm}$. The surprising result is the induction of free radicals in the visible light range of 400-700 $\mathrm{nm}$. On the background of these results, the authors propose the development of a new total sunlight protection factor based on a biological end point essential.

Watkinson and colleagues (Skin Pharmacol Physiol 2009; 22:15-21) studied the influence of ethanol on the solubility, ionisation and permeation characteristics of ibuprofen in silicone and human skin. In general, ethanol enhances the solubility of ibuprofen in the vehicle and both in silicone and in the skin. In the skin model the flux of ibuprofen was optimal for 50:50 and 75:25 ratios of ethanol to water. The lower ibuprofen flux from pure ethanol was seen as an influence of ethanol-induced skin dehydration.
Kobayashi and co-workers (Skin Pharmacol Physiol 2009; 22:45-48) showed in a letter to the editor that the antihistaminic drug bepotastine downregulates the cytokine/chemokine production and CD54 expression. The authors conclude that bepotastine exerts an anti-allergic activity on keratinocytes by suppressing the production of pro-inflammatory cytokines and both Th1 and Th2 chemokines.

The seasonal effects on the nasolabial skin condition were studied by De Paepe et al. (Skin Pharmacol Physiol 2009;22: $8-14)$ in 16 healthy volunteers. They were able to show that nasolabial TEWL, skin redness and desquamation were elevated during winter and autumn. As an underlying cause, functionally impaired hydro-lipid layers were detected during the winter season.

Novotný and colleagues (Skin Pharmacol Physiol 2009;22: 22-30) synthesized short-chain ceramide analogues with a polar head structure identical to ceramide NS. They studied their effect compared to physiological ceramide NS on skin permeability using porcine skin and the model drugs theophylline and indomethacine. Ceramides with a 4- to 8-carbon acyl chain increased skin permeability for both drugs up to 10.8 times. The authors state that short-chain ceramides do not act as natural ceramides and should be used with caution.

Proksch (Skin Pharmacol Physiol 2009;22:3-7) reviewed the protection against dryness of facial skin. The facial skin is exposed to a plethora of exogenous stress factors and requires special attention. The fact that facial skin has a thinner epidermis (especially on the eye lid) with a shortened turnover time has to be addressed when dry facial skin is to be treated. Proksch gives a comprehensive overview on the physiology of dry facial skin and a critical review of treatment strategies. The author suggests that 4 major components, namely hydrating ingredients, lipids and physiological lipids, ingredients to promote growth and differentiation and ingredients to soothe pruritus should be included.

We wish you a good start to a successful year 2009. Joachim Fluhr, President of the ISP Jürgen Lademann, Editor

\section{KARGER}

Fax +41613061234 E-Mail karger@karger.ch www.karger.com (c) 2009 S. Karger AG, Base

$1660-5527 / 09 / 0221-0001 \$ 26.00 / 0$

www.karger.com/spp 